\title{
Erratum to "Reproductive Success in Fish Stocks Can Be Reproduced by Environmental Factors Alone" [Open Access Library Journal, 2021, Volume 8: e7636]
}

\author{
Kazumi Sakuramoto \\ Department of Ocean Science and Technology, Tokyo University of Marine Science and Technology, Minato, Japan \\ Email: sakurak@kaiyodai.ac.jp
}

How to cite this paper: Sakuramoto, K. (2022) Erratum to "Reproductive Success in Fish Stocks Can Be Reproduced by Environmental Factors Alone" [Open Access Library Journal, 2021, Volume 8: e7636]. Open Access Library Journal, 9: e8231. https://doi.org/10.4236/oalib.1108231

Received: November 26, 2021

Accepted: January 8, 2022

Published: January 11, 2022

Copyright $\odot 2022$ by author(s) and Open Access Library Inc.

This work is licensed under the Creative Commons Attribution International License (CC BY 4.0).

http://creativecommons.org/licenses/by/4.0/ (c) (i) Open Access
The original online version of this article (Sakuramoto, K. (2021) Reproductive Success in Fish Stocks Can Be Reproduced by Environmental Factors Alone. Open Access Library Journal, 8: e7636.

https://doi.org/10.4236/oalib.1107636) unfortunately contains some mistakes. The author wishes to correct the errors in the following version:

\begin{abstract}
One error was found that the PDO data used in the previous paper were not the newest version. In the present study, the PDO data were replaced by the newest version. As a result of this error and incorporating recent RPS data, the AO and PDO data that were selected here to reproduce the reproductive successes (RPS) were thus different from those of the previous paper. This study showed that the RPS in fish stocks could be reproduced using only environmental factors. As the environmental factors, the monthly Arctic oscillation index and Pacific decadal oscillation were used. The RPS of 12 stocks harvested around Japan was reproduced. The results were as follows: the fitness between observed and reproduced RPS, and the number of the independent variables necessary for reproducing the RPS differed by stock. However, the fluctuations of RPS could be reproduced using only the environmental factors. These results support the validity of the mechanism proposed by Sakuramoto regarding the factors that drive the fluctuation in RPS. That is, the fluctuation in RPS occurs due to conditions determined by environmental factors, and is not a density-dependent effect.
\end{abstract}

\section{Subject Areas}

Marine Biology 


\section{Keywords}

Reproductive Successes, RPS, Chub Mackerel, Blue Mackerel, Alaska Pollock, Japanese Sardine, Japanese Anchovy, Japanese Common Squid, Arabesque Greenling, Splendid Alfonsino

\section{Introduction}

Reproductive successes (RPS) largely fluctuate every year. Such fluctuations cause the large variability in stock abundance. Therefore, the mechanism that controls the fluctuations in RPS is very important for managing fishery resources. Generally, it has been considered that a density-dependent effect is the essential factor driving fluctuations in RPS, while environmental factors have been considered only a perturbation factor.

However, Sakuramoto [1] [2] showed that the RPS of Pacific stock of Japanese sardines and Pacific bluefin tuna could be reproduced using only environmental factors. The model did not assume a density-dependent effect. As the main environmental factors, the sea surface temperature in the Kuroshio extension area was used for the former stock, and the monthly index of Arctic Oscillation (AO) and Pacific Decadal Oscillation (PDO) was used for the latter stock.

The aim of this paper is to investigate whether or not the mechanism proposed by Sakuramoto [1] [2] could be adapted to other stocks. That is, whether RPS could be reproduced using only environmental factors. In this study, only $\mathrm{AO}$ and PDO by monthly index were used as the environmental factors, and we attempted to reproduce the RPS for 12 stocks harvested around Japan.

The stocks investigated were: 1) Pacific stock of Chub mackerel (Scomber japonicus); 2) Tushima warm current stock of Chub mackerel; 3) Pacific stock of Blue mackerel (Scomber australasicous); 4) East China Sea stock of Blue mackerel; 5) Pacific stock of Alaska pollock (Teragra chalcogramma); 6) Northern Sea of Japan stock of Alaska pollock; 7) Pacific stock of Japanese sardine (Sardinops melanostictus); 8) Pacific stock of Japanese anchovy (Engraulis japonicus); 9) Autumn-spawning stock of Japanese common squid (Todarodes pacificus); 10) Winter-spawning stock of Japanese common squid; 11) Northern Sea of Japan stock of Arabesque greenling (Pleurogrammus azonus); 12) Pacific stock of Splendid alfonsino (Beryx splendens).

\section{Materials and Methods}

\subsection{Data}

The data for the stocks used in this study were provided by the Fisheries Agency and Fisheries Research Agency Japan [3]. The environmental factors used in this study were the monthly index of the AO [4] and PDO [5]. The PDO data were replaced by the newest version, because the PDO data that Sakuramoto [6] used were not the newest version. 


\subsection{Calculation of Correlation Coefficients between RPS and AO, and RPS and PDO, by Month}

The correlation coefficient between RPS in year $t\left(R P S_{t}\right)$ and the AO in month $m$ of year $t-i,\left(A O_{m, t-i}\right)$ were calculated. Here $m, t$ and $i$ denote the month, year and time lag, respectively. The correlation coefficient between RPS in year $t$ $\left(R P S_{t}\right)$ and the PDO in month $m$ of year $t-i,\left(P D O_{m, t-i}\right)$ were also calculated. Subsequently, $A O_{m, t-i}$ and $P D O_{m, t-i}$ that showed statistical significance were used as candidate independent variables in order to reproduce the RPS. That is,

$$
R P S_{t}=\exp \left(\text { Const. }+\sum_{m=1}^{12} \sum_{i=0}^{p} a_{m, t-i} A O_{m, t-i}+\sum_{m=1}^{12} \sum_{i=0}^{q} b_{m, t-i} P D O_{m, t-i}\right)
$$

Here, $a_{m, t-i}$ and $b_{m, t-i}$ were the partial regression coefficients that were used to reproduce the RPS. They were determined by each stock so as to minimize the sum of square values of observed and reproduced RPS.

\section{Results}

\section{Independent Variables and the Partial Regression Coefficients Used to Reproduce the RPS}

Table 1 lists the independent variables and partial regression coefficients estimated so as to minimize the differences between observed and reproduced RPS. For instance, in the case of the Pacific stock of Chub mackerel, February of AO in year $t-2$, January of AO in year $t-3$, August of PDO in year $t-1$, and September of PDO in year -2 were used as the independent variables to reproduce the RPS. For this stock, only four independent variables were needed, even though, except for several years, the fitness of observed and reproduced RPS were very high.

Table 1. Independent variables, the number of the independent variables (n) and the partial regression coefficients estimated to reproduce RPS.

\begin{tabular}{|c|c|c|c|}
\hline \multicolumn{2}{|c|}{ Chub mackerel (Pacific) (1970-2019) } & \multicolumn{2}{|c|}{$\begin{array}{l}\text { Chub mackerel (Tushima warm current) } \\
\qquad(1973-2019)\end{array}$} \\
\hline Const. & 2.14940 & Const. & 1.79832 \\
\hline $\mathrm{AO}_{t-2,2}$ & 0.19378 & $\mathrm{AO}_{t-1,5}$ & 0.21067 \\
\hline $\mathrm{AO}_{t-3,1}$ & 0.14160 & $\mathrm{PDO}_{t-2,3}$ & -0.16134 \\
\hline $\mathrm{PDO}_{t-1,8}$ & -0.28366 & $\mathrm{PDO}_{t-2,4}$ & 0.08336 \\
\hline \multirow[t]{4}{*}{$\mathrm{PDO}_{t-2,9}$} & -0.25682 & $\mathrm{PDO}_{t-3,10}$ & 0.14961 \\
\hline & & $\mathrm{PDO}_{t-3,11}$ & -0.17270 \\
\hline & & $\mathrm{PDO}_{t-4,9}$ & 0.02119 \\
\hline & & $\mathrm{PDO}_{t-4,10}$ & -0.14241 \\
\hline$n$ & 4 & $n$ & 7 \\
\hline \multicolumn{2}{|c|}{ Blue mackerel (Pacific) (1995-2019) } & \multicolumn{2}{|c|}{ Blue mackerel (East China Sea) (1992-2019) } \\
\hline Const. & 1.84545 & Const. & 1.63168 \\
\hline $\mathrm{AO}_{t, 4}$ & -0.41075 & $\mathrm{AO}_{t, 2}$ & -0.08519 \\
\hline
\end{tabular}




\section{Continued}

\begin{tabular}{|c|c|c|c|}
\hline $\mathrm{AO}_{t-3,9}$ & -0.46068 & $\mathrm{AO}_{t-3,9}$ & -0.18139 \\
\hline $\mathrm{AO}_{t-6,2}$ & 0.25503 & $\mathrm{AO}_{t-4,9}$ & 0.10050 \\
\hline $\mathrm{AO}_{t-6,3}$ & 0.79874 & $\mathrm{AO}_{t-6,6}$ & -0.11093 \\
\hline $\mathrm{AO}_{t-6,4}$ & -0.44011 & $\mathrm{PDO}_{t-2,3}$ & -0.08499 \\
\hline$n$ & 5 & $n$ & 5 \\
\hline \multicolumn{2}{|c|}{ Alaska pollock (Pacific) (1981-2019) } & \multicolumn{2}{|c|}{ Alaska pollock (Japan Sea) (1980-2017) } \\
\hline Const. & 1.90890 & Const. & 0.5830 \\
\hline $\mathrm{AO}_{t, 1}$ & 0.16949 & $\mathrm{PDO}_{t, 1}$ & 0.3932 \\
\hline $\mathrm{AO}_{t, 8}$ & 0.35289 & $\mathrm{PDO}_{t, 2}$ & -0.7903 \\
\hline $\mathrm{AO}_{t-1,6}$ & 0.43970 & $\mathrm{PDO}_{t, 3}$ & 0.9668 \\
\hline $\mathrm{PDO}_{t-2,12}$ & 0.22574 & $\mathrm{PDO}_{t, 4}$ & -0.3961 \\
\hline \multirow[t]{6}{*}{$\mathrm{PDO}_{t-3,12}$} & 0.23164 & $\mathrm{PDO}_{t-1,7}$ & 0.5287 \\
\hline & & $\mathrm{PDO}_{t-1,8}$ & -1.1441 \\
\hline & & $\mathrm{PDO}_{t-1,9}$ & 0.2270 \\
\hline & & $\mathrm{PDO}_{t-1,10}$ & 0.2689 \\
\hline & & $\mathrm{PDO}_{t-2,9}$ & -0.3519 \\
\hline & & $\mathrm{PDO}_{t-2,11}$ & 0.5752 \\
\hline$n$ & 5 & $n$ & 10 \\
\hline \multicolumn{2}{|c|}{ Japanese sardine (Pacific) (1976-2019) } & \multicolumn{2}{|c|}{ Japanese anchovy (Pacific) (1978-2019) } \\
\hline Const. & 3.01475 & Const. & 5.34338 \\
\hline $\mathrm{AO}_{t, 1}$ & -0.14214 & $\mathrm{PDO}_{t, 7}$ & -0.15766 \\
\hline $\mathrm{AO}_{t, 12}$ & -0.25989 & $\mathrm{PDO}_{t, 12}$ & 0.32754 \\
\hline $\mathrm{AO}_{t-4,10}$ & -0.17599 & $\mathrm{PDO}_{t-1,2}$ & 0.47451 \\
\hline $\mathrm{AO}_{t-6,8}$ & -0.43662 & $\mathrm{PDO}_{t-1,3}$ & -0.33761 \\
\hline $\mathrm{PDO}_{t-4,2}$ & -0.23275 & $\mathrm{PDO}_{t-1,11}$ & -0.12146 \\
\hline $\mathrm{PDO}_{t-5,2}$ & 0.14528 & $\mathrm{PDO}_{t-1,12}$ & 0.49996 \\
\hline $\mathrm{PDO}_{t-5,3}$ & -0.12771 & $\mathrm{PDO}_{t-2,4}$ & 0.19450 \\
\hline $\mathrm{PDO}_{t-5,4}$ & -0.14637 & & \\
\hline $\mathrm{PDO}_{t-6,2}$ & -0.14219 & & \\
\hline $\mathrm{PDO}_{t-6,7}$ & -0.15153 & & \\
\hline$n$ & 10 & $n$ & 7 \\
\hline \multicolumn{2}{|c|}{$\begin{array}{l}\text { Japanese common squid (Autumn) } \\
\text { (1982-2020) }\end{array}$} & \multicolumn{2}{|c|}{$\begin{array}{l}\text { Japanese common squid (Winter) } \\
\qquad(1980-2020)\end{array}$} \\
\hline Const. & 0.98183 & Const. & 1.10734 \\
\hline $\mathrm{AO}_{t, 1}$ & 0.08348 & $\mathrm{AO}_{t-2,4}$ & 0.14772 \\
\hline $\mathrm{AO}_{t-2,9}$ & 0.12985 & $\mathrm{AO}_{t-4,4}$ & -0.07341 \\
\hline $\mathrm{AO}_{t-5,5}$ & 0.19648 & $\mathrm{PDO}_{t-1,6}$ & -0.12944 \\
\hline $\mathrm{PDO}_{t-1,10}$ & -0.06729 & $\mathrm{PDO}_{t-3,6}$ & 0.04627 \\
\hline $\mathrm{PDO}_{t-4,7}$ & 0.10226 & $\mathrm{PDO}_{t-4,10}$ & 0.17227 \\
\hline $\mathrm{PDO}_{t-4,9}$ & 0.05925 & & \\
\hline$n$ & 6 & $n$ & 5 \\
\hline
\end{tabular}




\section{Continued}

\begin{tabular}{cccc}
\hline Arabesque greenling (Pacific) (1985-2019) & Splendid alfonsino (Pacific) (1999-2019) \\
\hline Const. & 2.34144 & Const. & -1.01640 \\
$\mathrm{AO}_{t, 8}$ & -0.37237 & $\mathrm{AO}_{t-4,7}$ & 0.37528 \\
$\mathrm{AO}_{t-1,1}$ & -0.11045 & $\mathrm{AO}_{t-6,3}$ & 0.14709 \\
$\mathrm{AO}_{t-1,7}$ & 0.38675 & $\mathrm{PDO}_{t-3,3}$ & 0.15714 \\
$\mathrm{PDO}_{t-2,2}$ & 0.31799 & $\mathrm{PDO}_{t-3,4}$ & -0.31603 \\
$\mathrm{PDO}_{t-5,1}$ & 0.34190 & $\mathrm{PDO}_{t-3,7}$ & -0.10595 \\
$\mathrm{PDO}_{t-5,11}$ & 0.13780 & $\mathrm{PDO}_{t-5,12}$ & -0.08927 \\
\hline$n$ & 6 & $n$ & 6
\end{tabular}

Figure 1 shows the observed (blue) and reproduced (red) RPS for the Pacific stock of Chub mackerel (A) and the Tushima warm current stock (B). In general, when observed RPS was extremely high or low, it was difficult to reproduce those levels exactly; however, the whole tendency of the observed RPS was relatively well reproduced using the model proposed here.
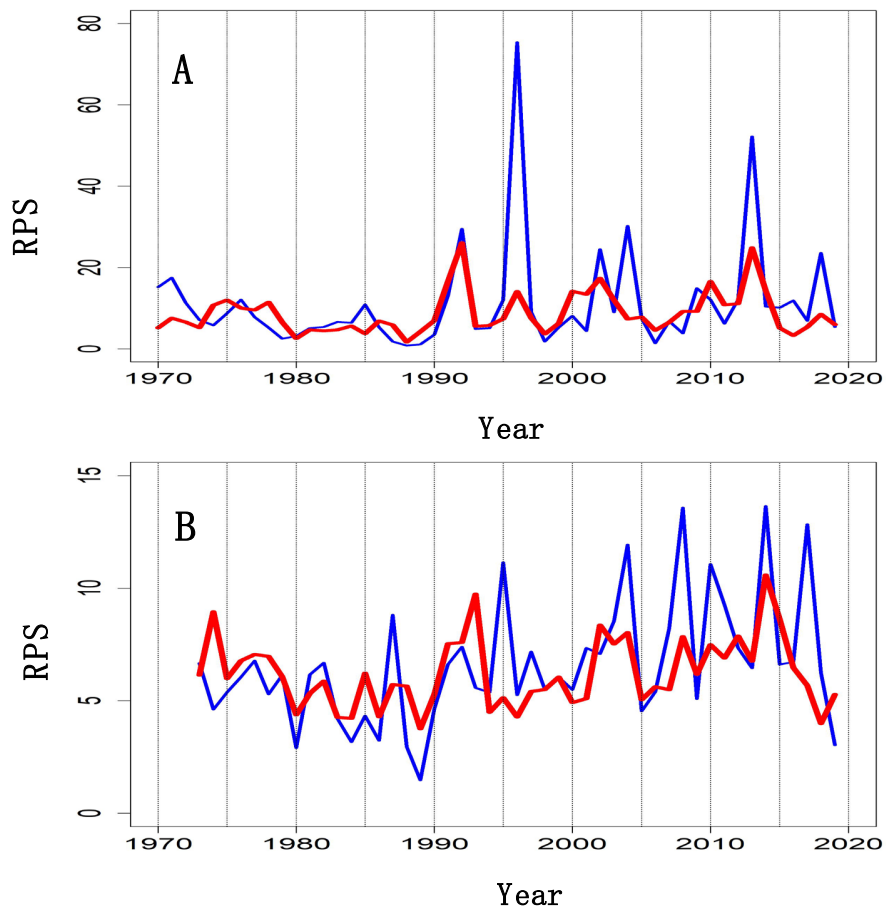

Figure 1. RPS observed (blue) and reproduced (red). (A) Pacific stock of Chub mackerel. (B) Tushima warm current stock.

Figure 2 shows the observed and reproduced RPS for the Pacific stock of Blue mackerel (A) and the East China Sea stock (B). In Figure 2, the observed and reproduced RPS did not coincide well in several years, however, the whole tendency of the observed RPS was relatively well reproduced. Figure 3 presents the observed and reproduced RPS for the Pacific stock of Alaska pollock (A) and Northern Sea of Japan stock (B). In the case of the Northern Sea of Japan stock 
(B), the observed and reproduced RPS did not coincide well. For this stock, other environmental factors should be incorporated to explain the fluctuation in RPS. Further analysis will be needed.
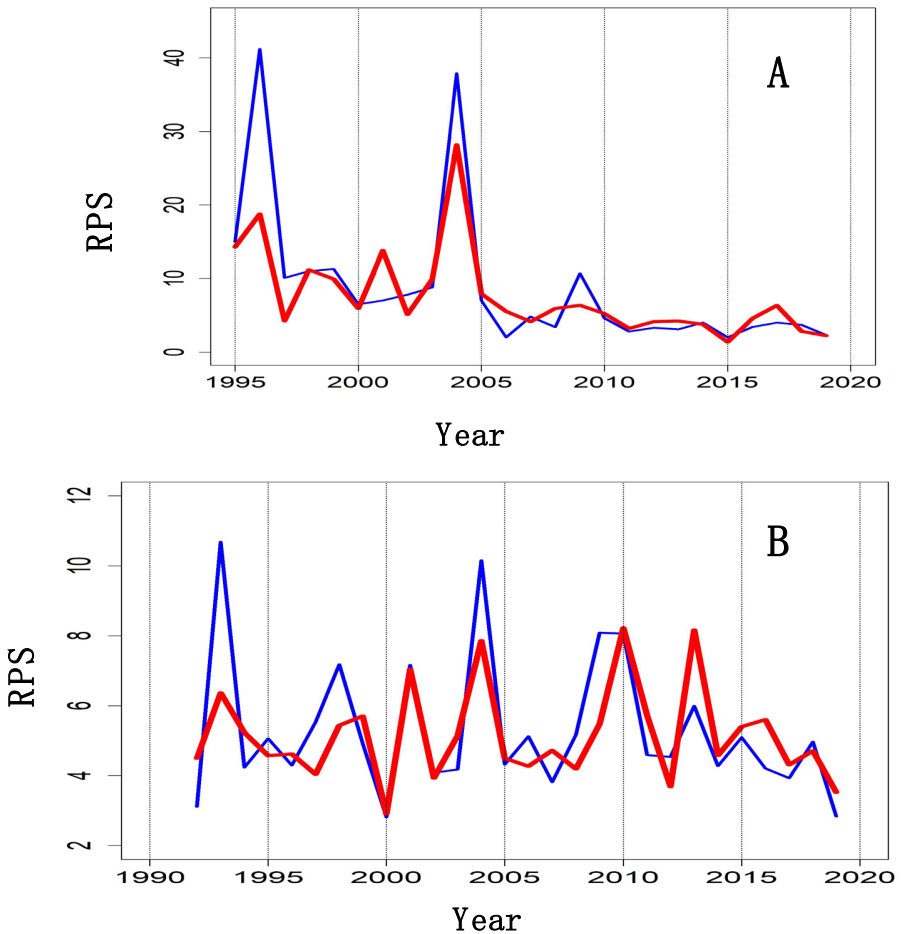

Figure 2. RPS observed (blue) and reproduced (red). (A) Pacific stock of Blue mackerel. (B) East China Sea stock of Blue mackerel.
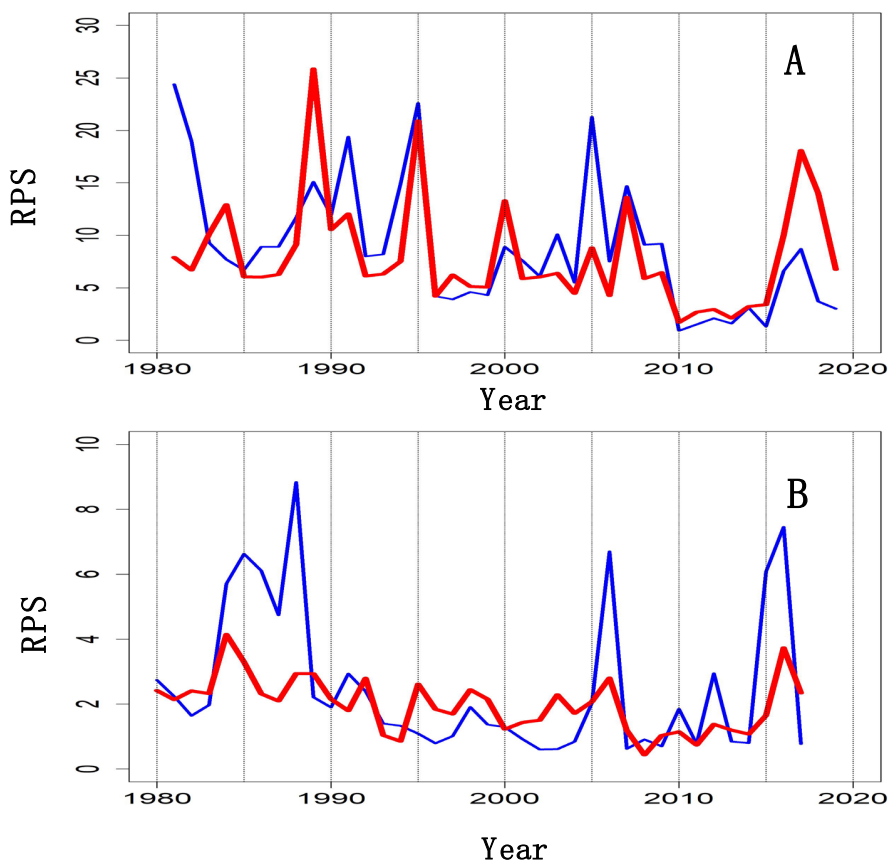

Figure 3. RPS observed (blue) and reproduced (red). (A) Pacific stock of Alaska pollock. (B) Northern Sea of Japan stock of Alaska pollock. 
Figure 4 contains the observed and reproduced RPS for the Pacific stock of Japanese sardine (A) and the Pacific stock of Japanese anchovy (B). The fluctuations of these two species were extremely large; however, the reproduced RPS was in good agreement with the observed RPS.
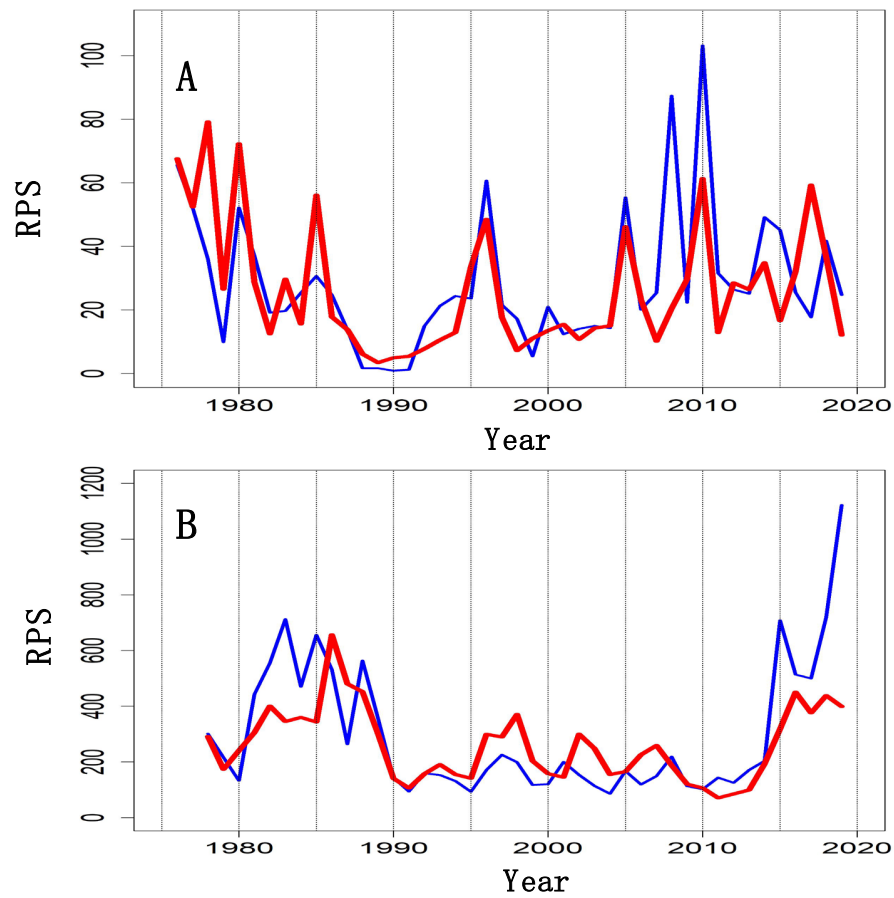

Figure 4. RPS observed (blue) and reproduced (red). (A) Pacific stock of Japanese sardine. (B) Pacific stock of Japanese anchovy.
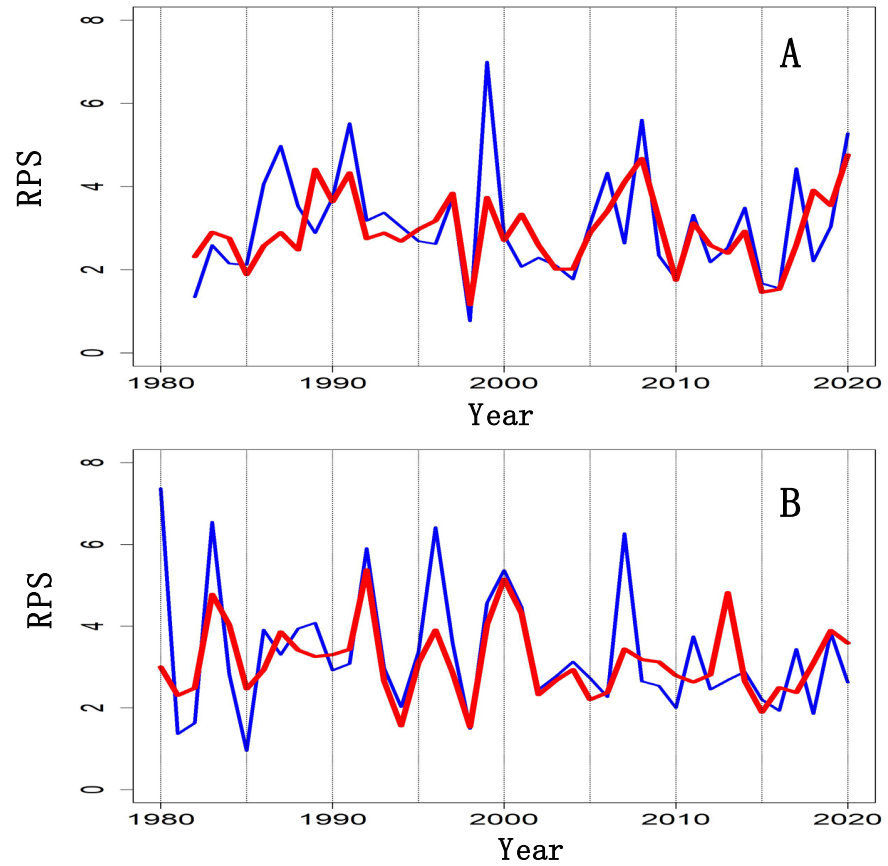

Figure 5. RPS observed (blue) and reproduced (red). (A) Autumn-spawning stock of Japanese common squid. (B) Winter-spawning stock of Japanese common squid. 
Figure 5 shows the observed and reproduced RPS for the Autumn-spawning stock of Japanese common squid (A) and that of the Winter-spawning stock (B). In both stocks, the whole tendency of the observed RPS was relatively well reproduced.

Figure 6 presents the observed and reproduced RPS for the Northern Sea of Japan stock of Arabesque greenling (A) and the Pacific stock of Splendid alfonsino (B). For the former stock, except for the latter of 2000s, the fitness of observed and reproduced RPS was very high. The latter stock, the RPS abruptly decreased in 2018 and 2019, and these sudden and rapid decreases were well reproduced with the model [7]. This indicates that the model proposed here is reasonable.
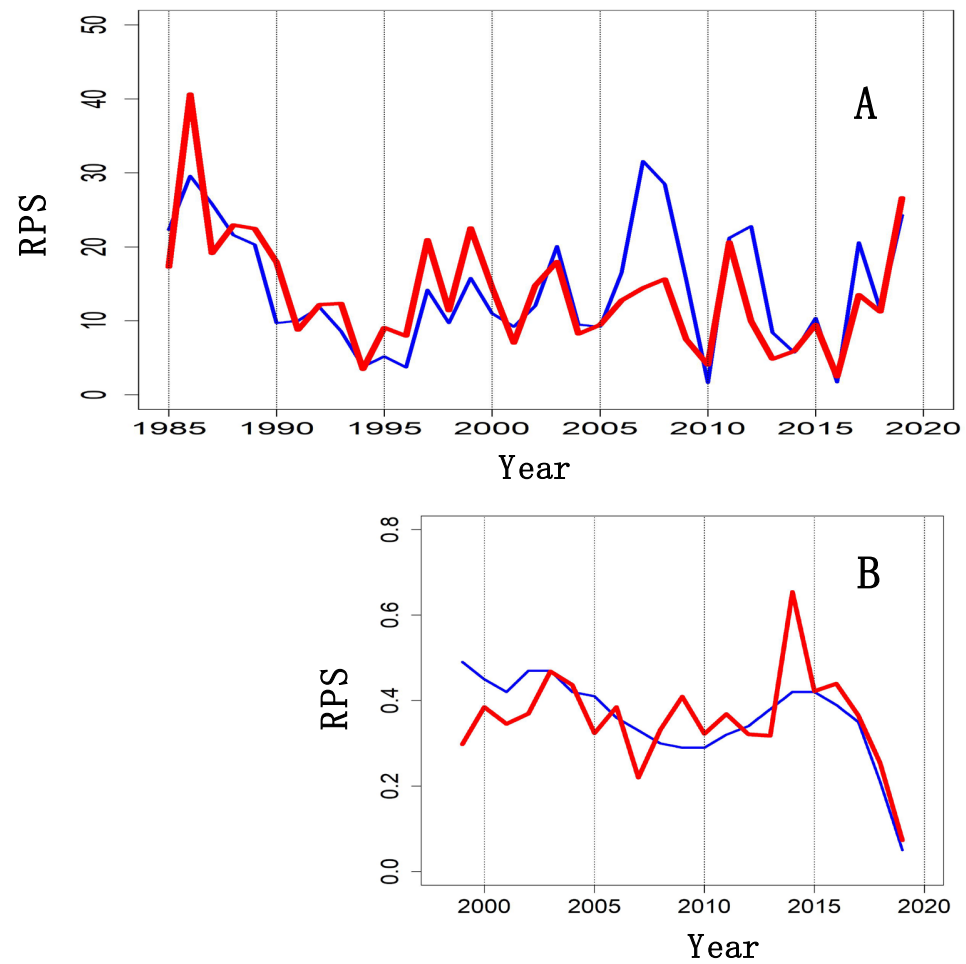

Figure 6. RPS observed (blue) and reproduced (red). (A) Northern Sea of Japan stock of Arabesque greenling. (B) Pacific stock of Splendid alfonsino.

\section{Discussion}

This study showed that RPS could be reproduced using only AO and PDO by month. A density-dependent effect, which is usually considered to be an important factor driving the RPS, was not needed to explain the large fluctuation in RPS. The models shown in this paper do not necessarily represent the best model to reproduce the RPSs, and much more reasonable models could be constructed if sufficient environmental information were available. This indicates that the important point that we should learn from this analysis is whether or not we can discover the best model to reproduce the RPS under limited environmental information. The more important point to learn from this analysis is 
that the overall fluctuations in RPS could be reproduced acceptably well even using the limited environmental information. This indicated that the RPS was mainly determined by environmental factors not a density-dependent effect. These results support the validity of the mechanism proposed by Sakuramoto [1] [2] [7] [8] [9] [10] [11] for the fluctuation in RPS. That is, the fluctuation in RPS occurs due to environmental conditions determined by environmental factors, not as a result of the density-dependent effect.

Generally, fisheries regulation is commenced based on the concept of maximum sustainable yield (MSY); however, the concept of MSY is established based on a density-dependent effect, for which the scientific basis is questionable. I recommend that fisheries regulation should be commenced using a new concept of population fluctuation that is free from the concept of MSY.

\section{Summary}

This study showed that reproductive successes (RPS) in fish stocks could be reproduced using only environmental factors. As the environmental factors, the monthly Arctic oscillation index and Pacific decadal oscillation were used. The RPS of 12 stocks harvested around Japan was investigated. The results were as follows: the fitness between observed and reproduced RPS, and the number of the independent variables necessary for reproducing the RPS differed by stock. However, the fluctuations of RPS could be reproduced using only the environmental factors. These results support the validity of the mechanism proposed by Sakuramoto regarding the factors that drive the fluctuation in RPS. That is, the fluctuation in RPS occurs due to conditions determined by environmental factors, and is not a density-dependent effect.

\section{Acknowledgements}

I thank anonymous reviewers for their useful comments that improved this manuscript.

\section{Conflicts of Interest}

The author declares no conflicts of interest.

\section{References}

[1] Sakuramoto, K. (2015) A Stock-Recruitment Relationship Applicable to Pacific Bluefin Tuna and the Pacific Stock of Japanese Sardine. American Journal of Climate Change, 4, 446-460. https://doi.org/10.4236/ajcc.2015.45036

[2] Sakuramoto, K. (2015) Illusion of a Density-Dependent Effect in Biology. Agricultural Sciences, 6, 479-488. https://doi.org/10.4236/as.2015.65047

[3] (2020) Fisheries Agency and Fisheries Research and Education Agency of Japan. https://www.abchan.fra.go.jp/digest2020/index.html/

[4] https://www.cpc.ncep.noaa.gov/products/precip/CWlink/daily_ao_index/monthly.a o. index.b50.current.ascii

[5] https://www.data.jma.go.jp/gmd/kaiyou/data/shindan/b_1/pdo/pdo.txt 
[6] Sakuramoto, K. (2021) Reproductive Success in Fish Stocks Can Be Reproduced by Environmental Factors Alone. Open Access Library Journal, 8, e7636. https://doi.org/10.4236/oalib.1107636

[7] Sakuramoto, K. (2021) A Model That Forecasts Future Values of Reproductive Success for the Pacific Stock of Splendid Alfonsino. Open Access Library Journal, 8, e8213. https://doi.org/10.4236/oalib.1108213

[8] Sakuramoto, K. (2013) A Recruitment Forecasting Model for the Pacific Stock of the Japanese Sardine (Sardinops melanostictus) That Does Not Assume Density-Dependent Effects. Agricultural Sciences, 4, 1-8. https://doi.org/10.4236/as.2013.46A001

[9] Sakuramoto, K. (2013) A Common Concept of Population Dynamics Applicable to both Thrips imaginis (Thysanoptera) and the Pacific Stock of the Japanese Sardine (Sardinops melanostictus). Fisheries and Aquatic Sciences. Sci, 2014, 140-151. https://doi.org/10.4172/2150-3508.1000085

[10] Sakuramoto, K. (2016) A Simulation Model of the Spawning Stock Biomass of Pacific Bluefin Tuna and Evaluation of Fisheries Regulations. American Journal of Climate Change, 5, 245-260. https://doi.org/10.4236/ajcc.2016.52021

[11] Sakuramoto, K. (2016) Density-Dependent Effect Occurs Regardless of Density. Open Access Library Journal, 3, e3112. https://doi.org/10.4236/oalib.1103112 